\title{
Mechanical Characterization of Lead-Free Sn-Ag-Cu Solder Joints by High-Temperature Nanoindentation
}

\author{
S. LOTFIAN, ${ }^{1}$ J.M. MOLINA-ALDAREGUIA, ${ }^{1,4}$ K.E. YAZZIE, ${ }^{3}$ \\ J. LLORCA, ${ }^{1,2}$ and N. CHAWLA ${ }^{3}$
}

\begin{abstract}
The reliability of $\mathrm{Pb}$-free solder joints is controlled by their microstructural constituents. Therefore, knowledge of the solder microconstituents' mechanical properties as a function of temperature is required. Sn-Ag-Cu lead-free solder alloy contains three phases: a Sn-rich phase, and the intermetallic compounds (IMCs) $\mathrm{Cu}_{6} \mathrm{Sn}_{5}$ and $\mathrm{Ag}_{3} \mathrm{Sn}$. Typically, the $\mathrm{Sn}$-rich phase is surrounded by a eutectic mixture of $\beta-\mathrm{Sn}, \mathrm{Cu}_{6} \mathrm{Sn}_{5}$, and $\mathrm{Ag}_{3} \mathrm{Sn}$. In this paper, we report on the Young's modulus and hardness of the $\mathrm{Cu}_{6} \mathrm{Sn}_{5}$ and $\mathrm{Cu}_{3} \mathrm{Sn}$ IMCs, the $\beta$-Sn phase, and the eutectic compound, as measured by nanoindentation at elevated temperatures. For both the $\beta$-Sn phase and the eutectic compound, the hardness and Young's modulus exhibited strong temperature dependence. In the case of the intermetallics, this temperature dependence is observed for $\mathrm{Cu}_{6} \mathrm{Sn}_{5}$, but the mechanical properties of $\mathrm{Cu}_{3} \mathrm{Sn}$ are more stable up to $200^{\circ} \mathrm{C}$.
\end{abstract}

\section{INTRODUCTION}

The elimination of lead from electronics due to its detrimental effects on the environment and health is pushing component manufacturers to use $\mathrm{Pb}$-free alloys. ${ }^{1-8}$ Replacing $\mathrm{Sn}-\mathrm{Pb}$ with $\mathrm{Pb}$-free solders has resulted in widespread study of materials properties, processing technology, and reliability. ${ }^{9,10}$ During service, interconnects will be exposed to relatively high temperatures, and the thermomechanical reliability of solder joints will be greatly affected by the mechanical properties of the individual microconstituents in the solder alloy; For instance, in the case of $\mathrm{Sn}-\mathrm{Ag}-\mathrm{Cu}$ (SAC) lead-free solder alloys, the solder contains three phases: a Sn-rich $\beta$-Sn phase, and the intermetallic compounds (IMCs) $\mathrm{Cu}_{6} \mathrm{Sn}_{5}$ and $\mathrm{Ag}_{3} \mathrm{Sn}$. The microstructure consists of Sn-rich dendrites surrounded by a eutectic mixture of $\beta-\mathrm{Sn}$ and $\mathrm{Ag}_{3} \mathrm{Sn}$, with small amounts of $\mathrm{Cu}_{6} \mathrm{Sn}_{5}$. Reflow of the solder material on $\mathrm{Cu}$ typically results in formation of $\mathrm{Cu}-\mathrm{Sn}$ intermetallic layers at the solder-Cu interface, which can influence the properties of the solder joint. Therefore, new methods are required to assess the mechanical properties of these phases, not only at room temperature but also at the high temperatures encountered in service. ${ }^{9,11}$

Previous studies have mainly focused on the room-temperature mechanical response of the individual phases. ${ }^{1,2,9,12-14}$ In this paper we report on high-temperature nanoindentation measurements of Young's modulus and hardness of several microconstituents in a Sn-3.9Ag-0.7Cu solder, in order to study the temperature dependence of the individual phases. Knowledge of the mechanical properties of individual phases as a function of temperature will be invaluable for obtaining a better understanding of the temperature-dependent behavior of these materials. It will also be invaluable in developing accurate constitutive equations for modeling solder joint behavior. 


\section{EXPERIMENTAL PROCEDURES}

Sn-3.9Ag-0.7Cu solder joints were prepared by melting $\mathrm{Sn}-3.9 \mathrm{Ag}-0.7 \mathrm{Cu}$ pellets (Indium Corp., Utica, NY, USA) between two polished oxygen-free high-conductivity $\mathrm{Cu}$ bars on a digital programmable hot plate (Torrey Pines Scientific, San Marcos, CA, USA). Details of the reflow procedure can be obtained elsewhere. ${ }^{15}$ The processing conditions were controlled in order to obtain two types of joints: (a) one with a thinner intermetallic layer but coarser solder microstructure, and (b) one with a relatively thick intermetallic layer but finer solder microstructures, as shown in Fig. 1. Joints of type (a) were used to obtain the properties of the pure $\beta$-Sn phase. The size of the intermetallic layer formed at the solder-Cu interface in type (a) joints was not sufficiently thick to provide accurate results from indentation. However, joints of type (b) enabled characterization of the $\mathrm{Cu}-\mathrm{Sn}$ intermetallic layers and the eutectic compound. Both types of joints were heated to $20^{\circ} \mathrm{C}$ above the melting point of Sn-3.9Ag$0.7 \mathrm{Cu}$, but were reflowed for different times: $40 \mathrm{~s}$ for joints of type (a) and $168 \mathrm{~h}$ for type (b). All samples were cut, and polished to a $0.05-\mu \mathrm{m}$ finish, with colloidal silica.
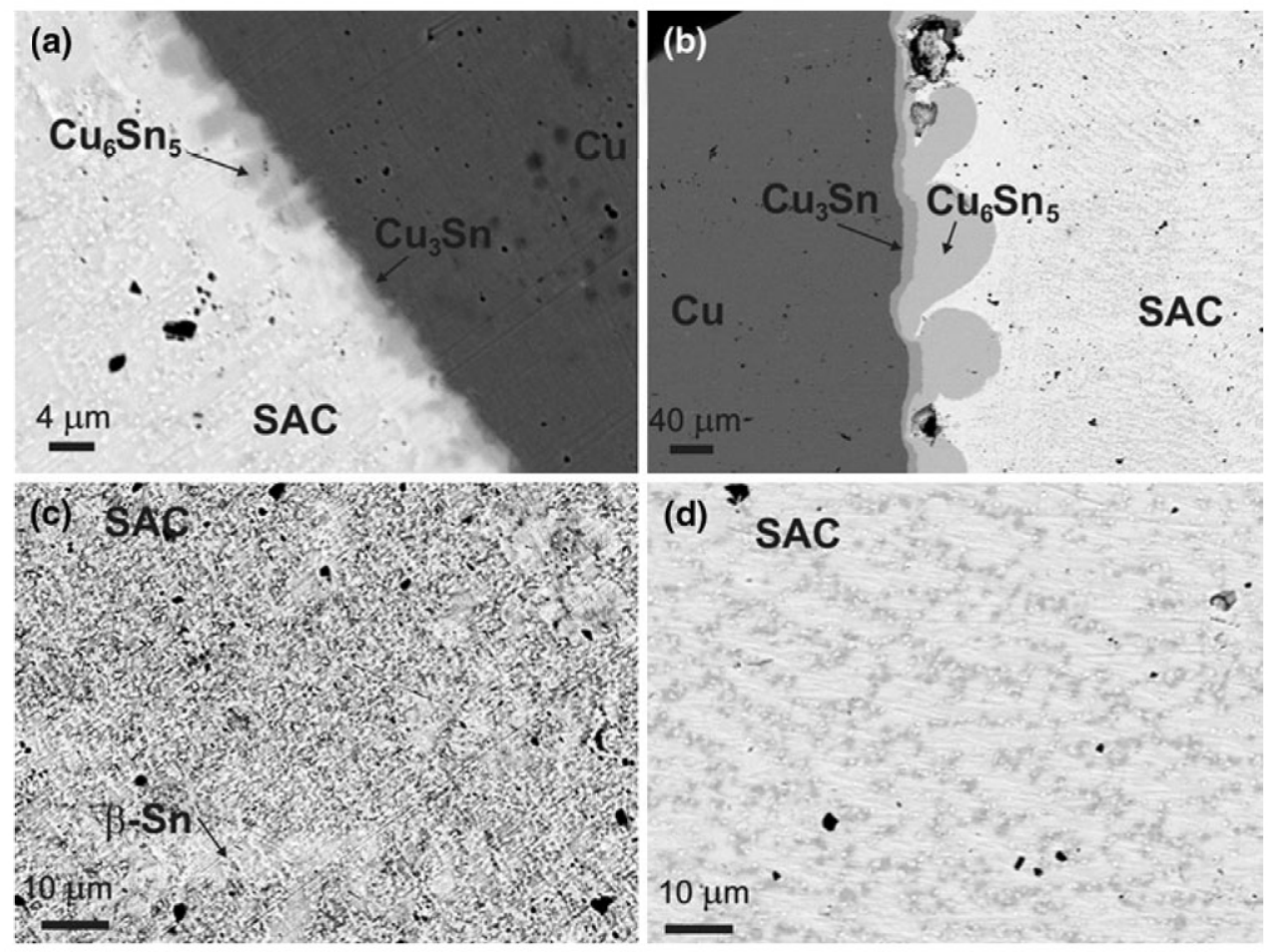

Fig. 1. Scanning electron microscopy (SEM) image of the Cu-SAC interface for (a) $40 \mathrm{~s}$ and (b) $168 \mathrm{~h}$ reflow time at $240^{\circ} \mathrm{C}$. Detail of the microstructure of the SAC for (c) $40 \mathrm{~s}$ and (d) $168 \mathrm{~h}$ reflow time.

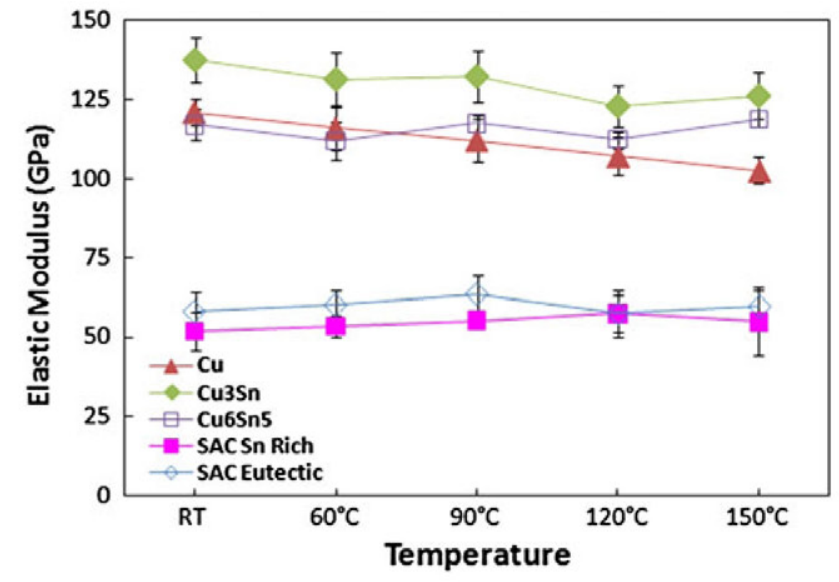

Fig. 2. Elastic modulus of each microconstituent as a function of temperature.

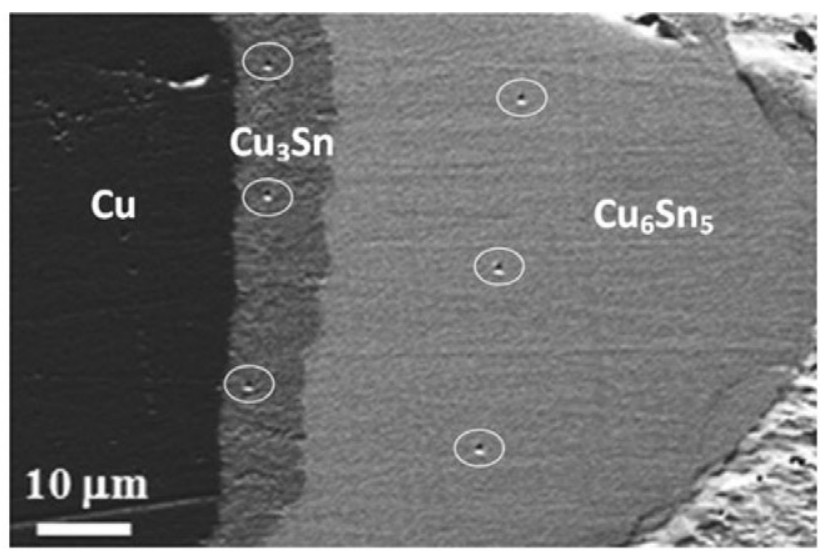

Fig. 3. Interface microstructure of $\mathrm{SAC}$ joint, showing $\mathrm{Cu}_{6} \mathrm{Sn}_{5}$ and $\mathrm{Cu}_{3} \mathrm{Sn}$ intermetallics. 
Table I. Elastic modulus of the different phases in the SAC solder joint

\begin{tabular}{|c|c|c|c|c|c|}
\hline $\begin{array}{l}\text { Elastic } \\
\text { Modulus (GPa) }\end{array}$ & RT & $60^{\circ} \mathrm{C}$ & $90^{\circ} \mathrm{C}$ & $120^{\circ} \mathrm{C}$ & $150^{\circ} \mathrm{C}$ \\
\hline $\mathrm{Cu}$ & $121 \pm 4$ & $116 \pm 6$ & $112 \pm 6$ & $107 \pm 6$ & $103 \pm 4$ \\
\hline $\mathrm{Cu}_{3} \mathrm{Sn}$ & $138 \pm 7$ & $132 \pm 8$ & $132 \pm 8$ & $123 \pm 6$ & $126 \pm 7$ \\
\hline $\mathrm{Cu}_{6} \mathrm{Sn}_{5}$ & $117 \pm 5$ & $111 \pm 6$ & $117 \pm 2$ & $112 \pm 2$ & $118 \pm 2$ \\
\hline Eutectic phase & $57 \pm 6$ & $60 \pm 5$ & $63 \pm 6$ & $57 \pm 7$ & $60 \pm 5$ \\
\hline Sn-rich phase & $52 \pm 6$ & $53 \pm 3$ & $55 \pm 2$ & $57 \pm 5$ & $55 \pm 10$ \\
\hline
\end{tabular}

Table II. Hardness of the different phases in the SAC solder joint

\begin{tabular}{|c|c|c|c|c|c|}
\hline Hardness (GPa) & RT & $60^{\circ} \mathrm{C}$ & $90^{\circ} \mathrm{C}$ & $120^{\circ} \mathrm{C}$ & $150^{\circ} \mathrm{C}$ \\
\hline $\mathrm{Cu}$ & $1.8 \pm 0.1$ & $1.7 \pm 0.2$ & $1.6 \pm 0.1$ & $1.54 \pm 0.06$ & $1.4 \pm 0.1$ \\
\hline $\mathrm{Cu}_{3} \mathrm{Sn}$ & $6.7 \pm 0.5$ & $6.4 \pm 0.5$ & $6.4 \pm 0.6$ & $5.6 \pm 0.4$ & $5.2 \pm 0.6$ \\
\hline $\mathrm{Cu}_{6} \mathrm{Sn}_{5}$ & $6.7 \pm 0.4$ & $6.6 \pm 0.6$ & $6.4 \pm 0.2$ & $5.1 \pm 0.1$ & $3.9 \pm 0.3$ \\
\hline Eutectic phase & $0.58 \pm 0.01$ & $0.37 \pm 0.05$ & $0.31 \pm 0.05$ & $0.22 \pm 0.03$ & $0.16 \pm 0.02$ \\
\hline Sn-rich phase & $0.31 \pm 0.01$ & $0.28 \pm 0.01$ & $0.26 \pm 0.01$ & $0.19 \pm 0.01$ & $0.15 \pm 0.01$ \\
\hline
\end{tabular}

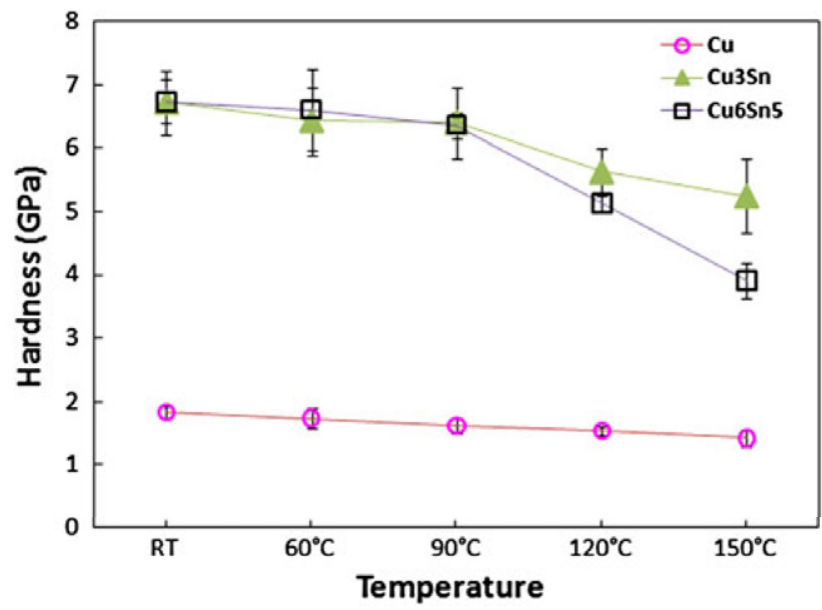

Fig. 4. Hardness of copper, $\mathrm{Cu}_{3} \mathrm{Sn}$, and $\mathrm{Cu}_{6} \mathrm{Sn}_{5}$.

Nanoindentation testing was carried out using a TI 950 Triboindenter ${ }^{\mathrm{TM}}$ (Hysitron, Inc., Minneapolis, $\mathrm{MN})$. The indentation tip assembly consists of a Berkovich-geometry diamond tip brazed to a low thermal expansion coefficient Zerodur ${ }^{\circledR}$ shaft, attached directly to the load transducer behind a heat shield. Nanoindentation testing was carried out at room temperature, $60^{\circ} \mathrm{C}, 90^{\circ} \mathrm{C}, 120^{\circ} \mathrm{C}$, and $150^{\circ} \mathrm{C}$. Ten different samples were used, one for each test temperature. Each sample was placed on the heater plate and subsequently heated to the target temperature. The indenter was then placed in contact with the sample using a small contact load $(2 \mu \mathrm{N})$, and contact was maintained for at least 30 min prior to the first indentation test, to allow for thermal stabilization of the system. Using this approach, typical drift rates of $0.1 \mathrm{~nm} \mathrm{~s}^{-1}$ were

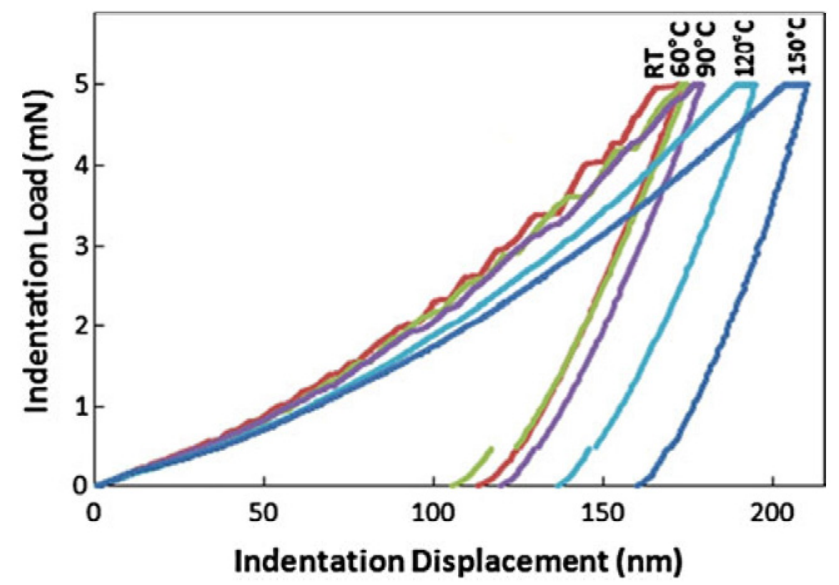

Fig. 5. Indentation load-displacement curves of $\mathrm{Cu}_{6} \mathrm{Sn}_{5}$ at different temperatures.

achieved. Two types of indentation tests were carried out at room temperature: conventional loadingunloading up to a maximum load of $5 \mathrm{mN}$, and multiple loading-unloading cycles to extract hardness and modulus as a function of indentation depth. The indentations were carried out at a loading rate of $2.5 \mathrm{mN} \mathrm{s}^{-1}$ with a hold period of $0.2 \mathrm{~s}$ at maximum load. This procedure helped to minimize creep effects on the measurement of the Young's modulus from the unloading stiffness. Upon unloading, drift was measured by introducing a $20 \mathrm{~s}$ hold segment at $10 \%$ of the maximum load. The drift rate was measured over the last $10 \mathrm{~s}$ of the hold segment. At least 10 indentations were performed at each temperature, and the samples were kept at the test temperature for at least $4 \mathrm{~h}$. The load 

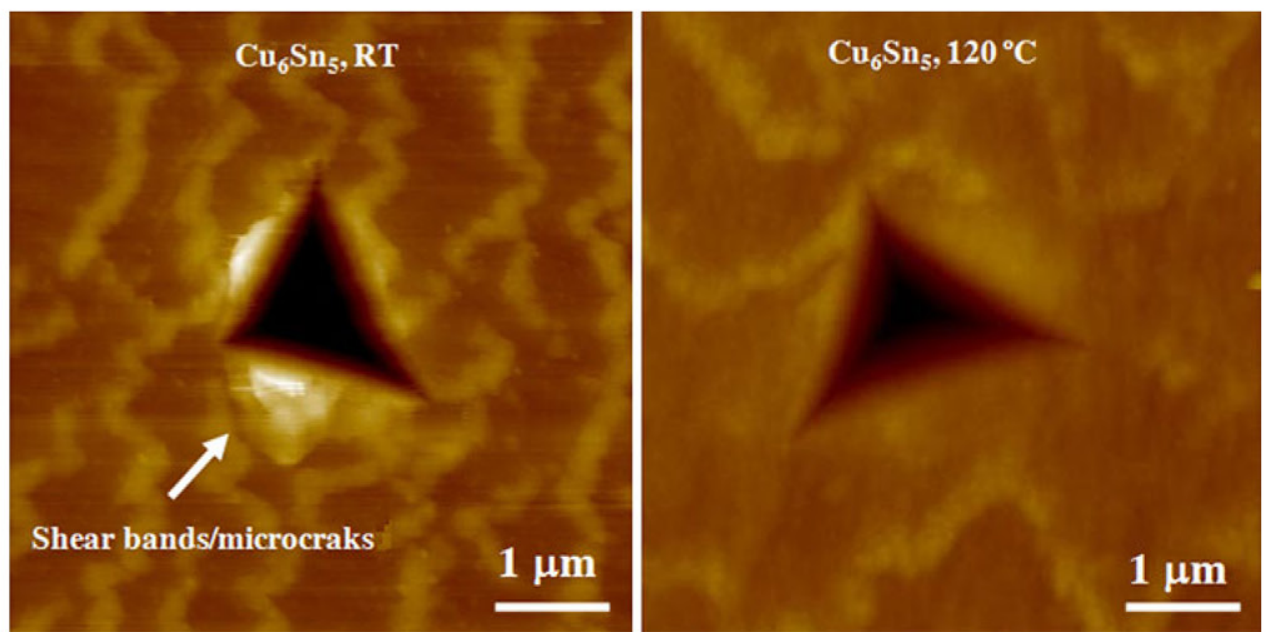

Fig. 6. AFM surface morphology of indentation in $\mathrm{Cu}_{6} \mathrm{Sn}_{5}$ at $\mathrm{RT}$ and $120^{\circ} \mathrm{C}$.

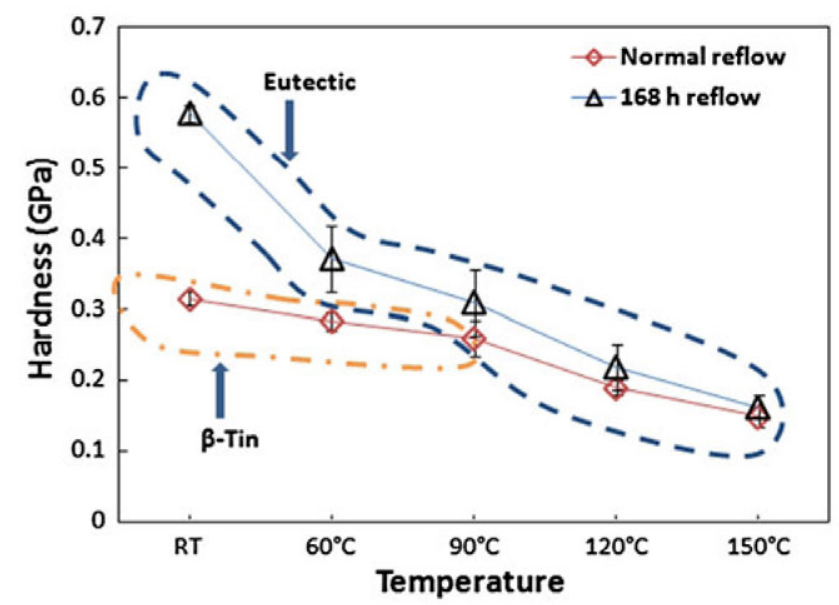

Fig. 7. Hardness of phases in SAC solder: Sn-rich phase and eutectic.

-displacement curves were analyzed using the Oliver and Pharr method. ${ }^{16}$

To carry out a more detailed analysis, selected indentations were further characterized by atomic force microscopy (AFM) to study pile-up/sink-in effects using a Park XE-150 instrument (Park Systems, Suwon, Korea). Scanning electron microscopy (SEM, EVO ${ }^{\circledR}$ MA15; Carl Zeiss) provided microstructural details, such us the distribution of phases in the solder and the intermetallic interlayer thicknesses. Chemical analysis was performed by energy-dispersive spectroscopy (EDS) using an Oxford INCA 350 microanalysis system attached to the SEM.

\section{RESULTS AND DISCUSSION}

Figure 2 plots the elastic modulus of each phase in the solder joint with increasing temperature, assuming the following Poisson's ratios for each phase: 0.3 for $\mathrm{Cu}_{3} \mathrm{Sn}, 0.31$ for $\mathrm{Cu}_{6} \mathrm{Sn}_{5}, 0.34$ for copper, and 0.4 for the SAC solder (close to the Poisson's ratio for pure $\mathrm{Sn})^{14}$. Results for the indentation modulus at room temperature are in good agreement with published studies on bulk alloys or solder joints. ${ }^{1,2}$ Figure 2 shows that the Young's moduli of the two intermetallics remain almost constant with temperature, while the elastic modulus of copper decreases around $15 \%$ at $150^{\circ} \mathrm{C}$, in good agreement with literature data for $\mathrm{Cu}^{17} \mathrm{In}$ the case of the SAC solder, due to the size of the $\beta$-Sn grains and the $\beta$-Sn/ $/ \mathrm{Ag}_{3} \mathrm{Sn}$ eutectic domains, only small $2-\mathrm{mN}$ indents were performed to ensure that the indents were fully contained in a single phase/domain. In both cases, the elastic moduli were relatively insensitive to temperature, with an average elastic modulus at room temperature of $52 \mathrm{GPa}$ for the Sn-rich phase and $68 \mathrm{GPa}$ for the eutectic. This can be explained by the higher modulus ( $\sim 90 \mathrm{GPa}$ ) of the $\mathrm{Ag}_{3} \mathrm{Sn}$ particles embedded in the Sn matrix. The elastic modulus results are summarized in Table I, where the errors represent one standard deviation.

Figure 3 shows the microstructure of the sample reflowed for $168 \mathrm{~h}$. Large intermetallic layers of $\mathrm{Cu}_{6} \mathrm{Sn}_{5}$ and $\mathrm{Cu}_{3} \mathrm{Sn}$ were observed. Note that the indentations are much smaller than the intermetallic phase thickness, and reside completely within a layer. Figures 1 and 3 show that the initial morphology of the intermetallic interlayers was very much dependent upon thermal aging. The $\mathrm{Cu}_{3} \mathrm{Sn}$ layer had a planar morphology and consisted of finer, columnar grain structure, compared with $\mathrm{Cu}_{6} \mathrm{Sn}_{5}$ that formed as large scallops due to a thermal grooving mechanism, as discussed in previous studies. ${ }^{2,15,18,19}$

The hardness results are summarized in Table II. Figure 4 shows the hardness of the copper substrate and the two IMCs. The decrease in the hardness of 

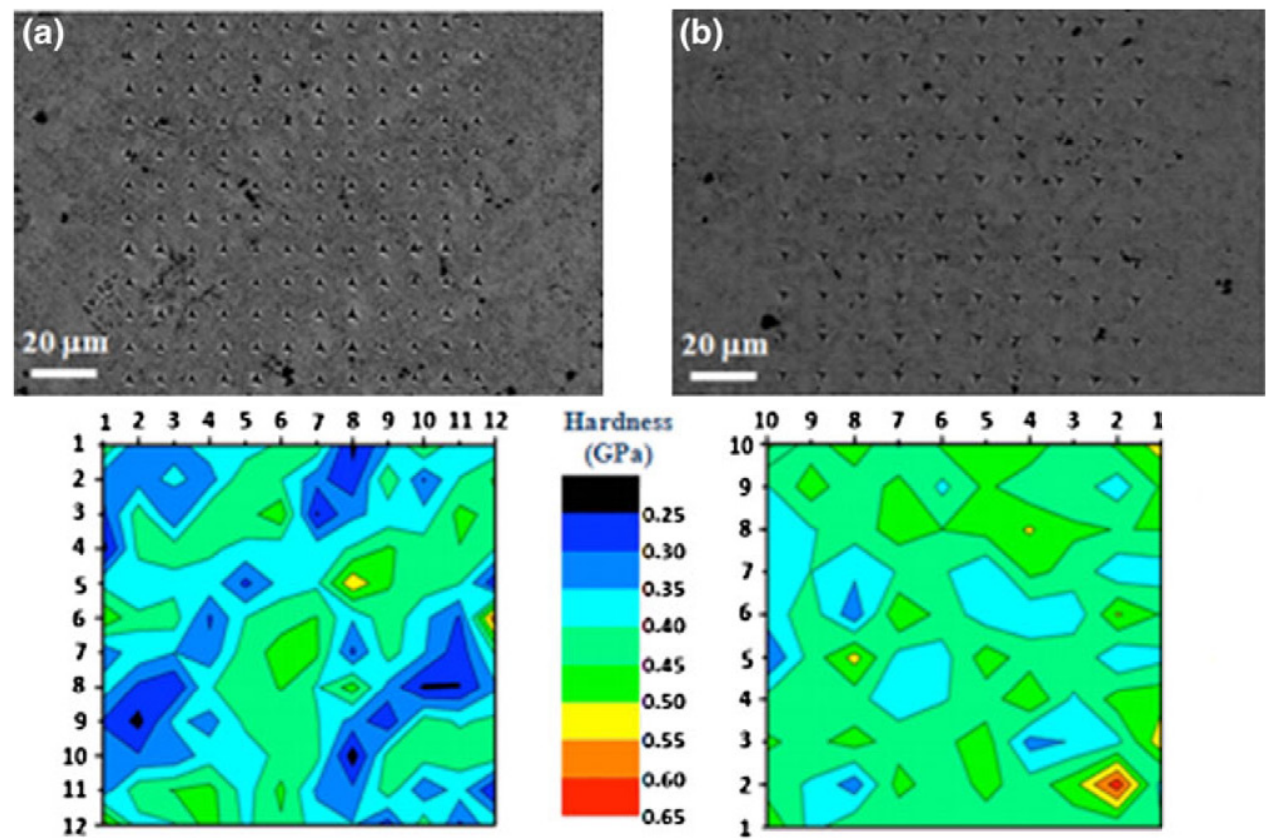

Fig. 8. Hardness map at room temperature of reflowed samples: (a) $40 \mathrm{~s}$ reflow time and (b) $168 \mathrm{~h}$ reflow time.
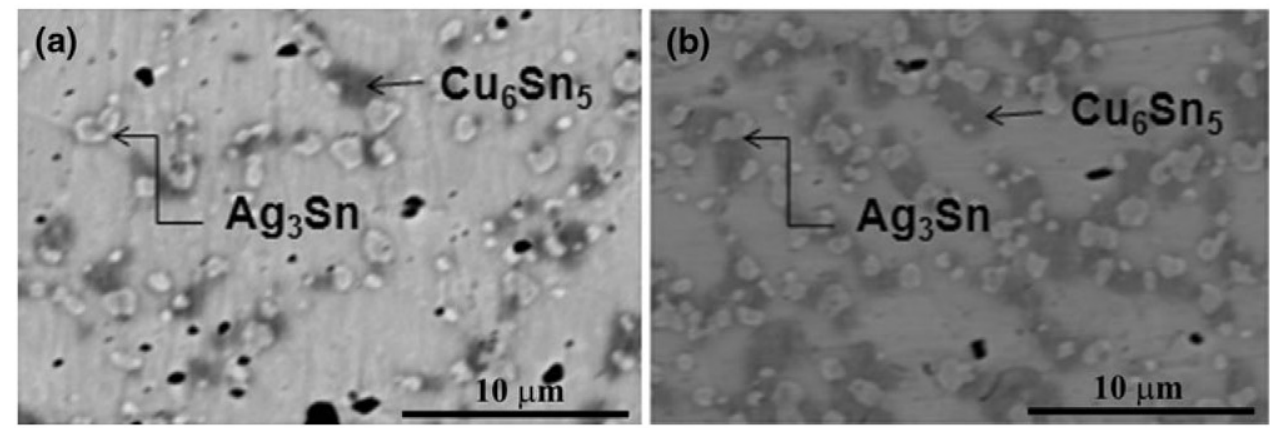

Fig. 9. Evolution of the microstructure during high-temperature $\left(150^{\circ} \mathrm{C}\right)$ testing of the samples for (a) $40 \mathrm{~s}$ reflow time and (b) $168 \mathrm{~h}$ reflow time.

$\mathrm{Cu}$ is consistent with the expected behavior for pure $\mathrm{Cu}$. The two intermetallics show a distinct behavior, with constant hardness up to $90^{\circ} \mathrm{C}$, after which the hardness starts to decrease, more strongly in the case of $\mathrm{Cu}_{6} \mathrm{Sn}_{5}$. The drop in hardness in $\mathrm{Cu}_{6} \mathrm{Sn}_{5}$, and to a lesser extent in $\mathrm{Cu}_{3} \mathrm{Sn}$, is accompanied by a change in the appearance of the load-displacement curves before and after $90^{\circ} \mathrm{C}$, as shown in Fig. 5 .

The load-displacement curves below $90^{\circ} \mathrm{C}$ show multiple pop-ins, characteristic of shear band formation or microcracking. ${ }^{20}$ Above $90^{\circ} \mathrm{C}$, the curves are smooth, with no evidence of cracking, and characteristic of a more ductile deformation behavior. The results suggest a brittle-to-ductile transition in the deformation behavior of the intermetallic phases (Fig. 5). AFM was used to quantify the surface profile of the indentations in each phase. The topography results in $\mathrm{Cu}_{6} \mathrm{Sn}_{5}$ show distinct features in the deformation pattern below and above $90^{\circ} \mathrm{C}$. At room temperature, the pile-up around the indent contrasts with a more homogeneous flow around the indentations at $120^{\circ} \mathrm{C}$. The pile-up at room temperature shows abrupt steps, but does not give rise to an increase in the contact area. This is indicative of the formation of shear bands and/or microcracks, which can explain the multiple pop-ins observed during loading below $90^{\circ} \mathrm{C}$ (Fig. 6). These features are not observed at $120^{\circ} \mathrm{C}$, which, together with the smoother loading behavior, reinforces the suggested brittle-to-ductile transition in the behavior of both $\mathrm{Cu}_{3} \mathrm{Sn}$ and $\mathrm{Cu}_{6} \mathrm{Sn}_{5}$ intermetallics. This brittle-to-ductile transition might be associated with the activation of dislocation flow, which explains the stronger temperature dependence observed in the hardness at temperatures above $90^{\circ} \mathrm{C}$ in Fig. 3. However, careful transmission electron microscopy (TEM) study of the area under the indents would be required to confirm this.

In the case of the SAC solder, the difference in hardness between the $\beta$-Sn-rich phase and the eutectic compound is $\sim 100 \%$ at room temperature, but this difference tends to decrease with temperature, with the 
(a) $\beta$-Sn
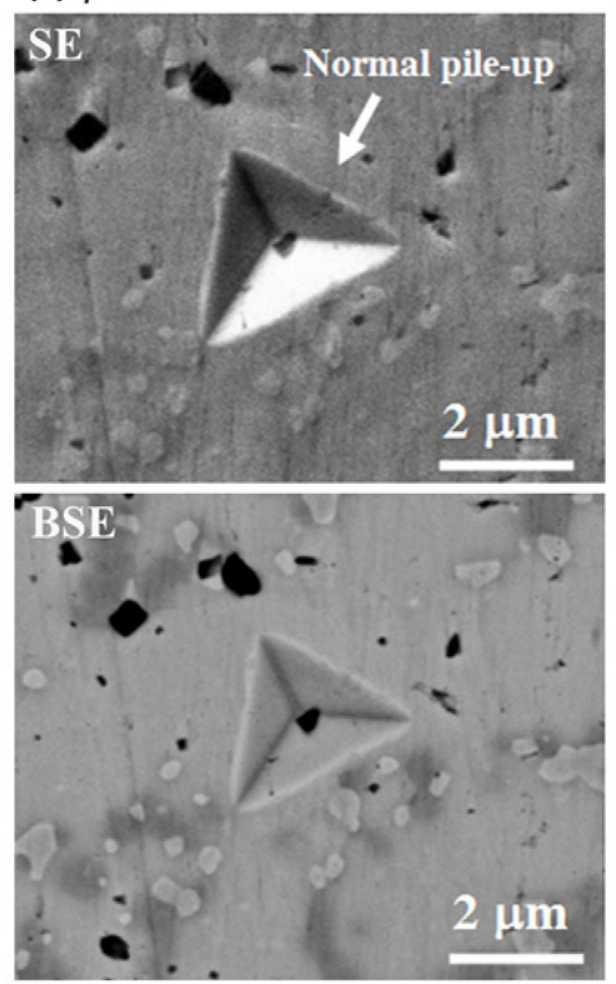

(b) Eutectic
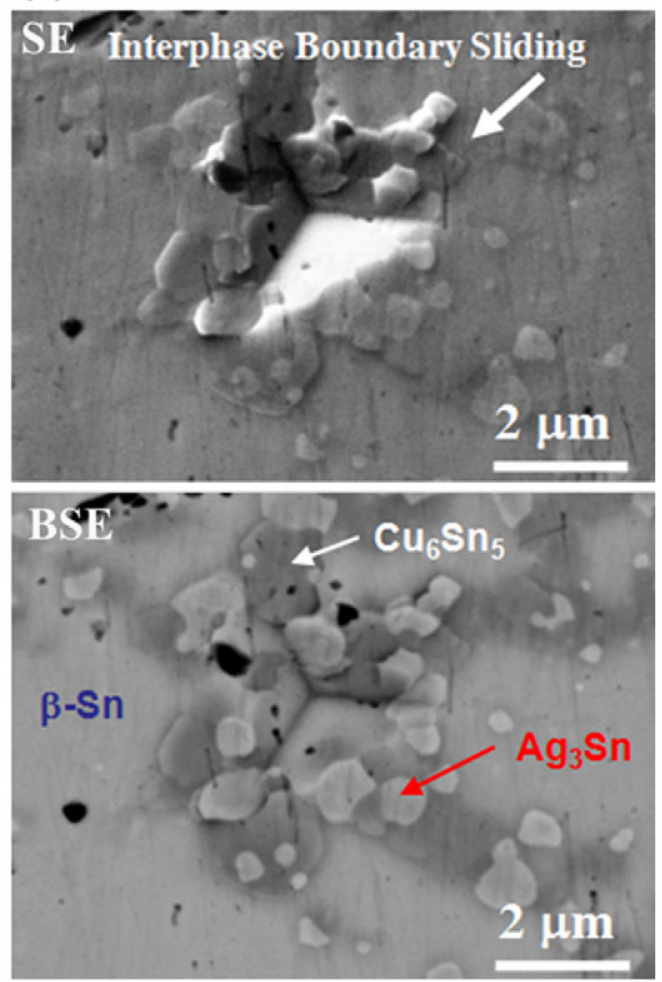

Fig. 10. Secondary electron (SE) and backscatter electron (BSE) images of indentation imprints on (a) $\beta$-Sn and (b) the eutectic compound.

hardness being identical at $150^{\circ} \mathrm{C}$ (Fig. 7; Table II). The reported $\mathrm{Ag}_{3} \mathrm{Sn}$ hardness at room temperature is $3.2 \mathrm{GPa}$, measured in bulk samples, which is consistent with the hardness difference between the $\beta$-Sn-rich phase and the eutectic compound ${ }^{1}$ at room temperature.

However, the evolution with temperature is more difficult to understand. The results suggest that above $90^{\circ} \mathrm{C}$ both $\beta$-Sn and the eutectic compound display the same hardness, but we believe that this is due to the microstructural evolution of the solder material at the high temperature of the tests (homologous temperatures higher than 0.7). Indeed, Fig. 8 plots hardness maps for the two initial samples studied: (a) normal reflow and (b) $168 \mathrm{~h}$ reflow. The maps correlate well with the initial microstructure and the distribution of $\mathrm{Ag}_{3} \mathrm{Sn}$ and $\mathrm{Cu}_{6} \mathrm{Sn}_{5}$ particles within the $\beta$-Sn phase (Fig. 8).

In this sense, sample (a) initially contained larger $\beta$-Sn-rich particles where the hardness of this phase could be computed at room temperature, while the solder in sample (b) presented a more homogeneous microstructure, so that the hardness is representative of the eutectic compound. However, it was noticed that, for testing temperatures above $90^{\circ} \mathrm{C}$, the microstructure in sample (a) tended to homogenize, so that the microstructures of both samples were identical at testing temperatures of $150^{\circ} \mathrm{C}$ (Fig. 9). Therefore, the results in Fig. 7 corresponding to the sample with the $40 \mathrm{~s}$ reflow time can only be attributed to $\beta$-Sn up to $90^{\circ} \mathrm{C}$, while for higher temperatures both samples provided the same results, corresponding to the eutectic compound.

According to these results, it is clear from Fig. 7 that the temperature dependence of the hardness is much stronger for the eutectic compound than for the $\beta$-Sn phase. This is expected based on the major contribution of interface sliding and coarsening of $\mathrm{Ag}_{3} \mathrm{Sn}$ in the case of the eutectic compound, as demonstrated in Fig. 10. Figure 10a shows a residual imprint in $\beta$-Sn phase showing a homogeneous deformation pattern. However, Fig. 10b shows the corresponding residual imprint in the eutectic, showing the major contribution of interphase boundary sliding in this case (Fig. 9), which can explain the strong temperature dependence of the hardness results.

\section{CONCLUSIONS}

High-temperature nanoindentation has proven very useful to measure the Young's modulus and hardness values of the individual phases present in a $\mathrm{Sn}-3.9 \mathrm{Ag}-0.7 \mathrm{Cu}$ solder joint as a function of temperature. In particular, the properties of the $\mathrm{Cu}_{6} \mathrm{Sn}_{5}$ and $\mathrm{Cu}_{3} \mathrm{Sn}$ intermetallics, the $\beta$-Sn phase, and the SAC eutectic compound have been measured in the temperature range between room temperature and $150^{\circ} \mathrm{C}$. The results at room temperature are in good 
agreement with previous results. No data have been reported so far at high temperatures, but our results suggest that the $\mathrm{Cu}_{6} \mathrm{Sn}_{5}$ and $\mathrm{Cu}_{3} \mathrm{Sn}$ intermetallics display a brittle-to-ductile transition at $90^{\circ} \mathrm{C}$. In the case of $\beta-\mathrm{Sn}$, it is not possible to assess the properties of $\beta$-Sn dendrites at temperatures above $90^{\circ} \mathrm{C}$, due to the homogenization of the microstructure at the testing temperature. The hardness of the eutectic Sn-3.9Ag-0.7Cu compound displays a very strong temperature dependence, presumably due to the role of interphase boundary sliding in the mechanical properties. Accurate and reliable determination of the hardness and Young's modulus values of these phases is of great importance for the study of the mechanical reliability of solder joints.

\section{ACKNOWLEDGEMENTS}

S.L., J.M.M.-A., and J.L. acknowledge the financial support of the Spanish Ministry of Science and Innovation (MAT2009-14396) and the Comunidad de Madrid through the program ESTRUMAT (S2009/MAT-1585). K.E.Y. and N.C. are grateful for the financial support for this work from the United States National Science Foundation Division of Materials Research-Metals Division (Drs. Alan Ardell, Bruce MacDonald, and Harsh Chopra, Program Directors).

\section{REFERENCES}

1. X. Deng, N. Chawla, K.K. Chawla, and M. Koopman, Acta Mater. 52, 4291 (2004)

2. X. Deng, M. Koopman, N. Chawla, and K.K. Chawla, Mater. Sci. Eng. A 364, 240 (2004).

3. F. Gao and T. Takemoto, Mater. Lett. 60, 2315 (2006).

4. J. Glazer, Int. Mater. Rev. 40, 65 (1995)

5. J. Glazer, J. Electron. Mater. 23, 693 (1994)

6. M. McCormack and S. Jin, JOM 45(7), 36 (1993).

7. W.J. Plumbridge, J. Mater. Sci. 31, 2501 (1996).

8. P. Vianco and D. Frear, JOM 45(7), 14 (1993).

9. N. Chawla, Int. Mater. Rev. 54, 368 (2009).

10. H. Zhiheng, L. Changqing, P. Conway, and R. Thomson, HDP '04. Proceeding of the Sixth IEEE CPMT Conference, vol. $52(2004)$

11. F. Gao, H. Nishikawa, T. Takemoto, and J. Qu, Microelectron. Reliab. 49, 296 (2009).

12. R.R. Chromik, R.P. Vinci, S.L. Allen, and M.R. Notis, J. Mater. Res. 18, 2251 (2003).

13. Y. Sun, J. Liang, Z.-H. Xu, G. Wang, and X. Li, J. Mater. Sci. Mater. Electron. 19, 514 (2007).

14. P.-F. Yang, Y.-S. Lai, S.-R. Jian, J. Chen, and R.-S. Chen, Mater. Sci. Eng. A 485, 305 (2008).

15. X. Deng, G. Piotrowski, J.J. Williams, and N. Chawla, J. Electron. Mater. 32, 1403 (2003).

16. W.C. Oliver and G.M. Pharr, J. Mater. Res. 7, 1564 (1992),

17. J.C. Trenkle, C.E. Packard, and C.A. Schuh, Rev. Sci. Instrum. 81, 073901 (2010).

18. F. Guo, S. Choi, J.P. Lucas, and K.N. Subramanian, J. Electron. Mater. 29, $1241(2000)$.

19. G. Zeng, S. Xue, L. Zhang, L. Gao, W. Dai, and J. Luo, J. Mater. Sci. Mater. Electron. 21, 421 (2010).

20. L. Jiang and N. Chawla, Scripta Mater. 63, 480 (2010). 